\title{
Use of sachet alcohol and sexual behaviour among adolescents in Ibadan, Nigeria
}

\author{
Oluwaseunfunmi Arasi ${ }^{1}$, Ademola Ajuwon ${ }^{2}$
}

1.Youth Empowerment Foundation, Monitoring \& Evaluation Department.

2. Department of Health Promotion \& Education, College of Medicine, University of Ibadan.

\begin{abstract}
Background: Availability and affordability of sachet liquor has significantly increased adolescents' access to alcohol in Nigeria. This study investigated use of sachet alcohol and sexual behavior among adolescents in Ibadan South-East Local Government Area(IBSE-LGA), Oyo state, Nigeria.

Methods: A descriptive cross-sectional study was conducted with three-stage random sampling technique to select 390 adolescents in IBSE-LGA, Oyo state; using quantitative and qualitative instruments(5 IDIs).

Results: There were more male adolescents (61.8\%); with $14.7 \pm 2.6$ as mean age; equal proportion of early (10-14years) and late(15-19years) adolescents. Findings show that about $16 \%$ of the respondents have not completed Primary School education; half $(50 \%)$ of the respondents had ever taken alcohol, while $39.5 \%$ are current users of sachet alcohol (more males, older adolescents and working class). Many respondents are sexually active(30.5\%), out of which $63 \%$ did not use any protection in their last sex episode, and 33.6\% tok sachet alcohol before sex. There was an association between sachet alcohol use and risky sexual behaviours $(\mathrm{p}<0.05)$. Participants of IDI believe alcohol boosts sexual performance.

Conclusion: Sex, age and school/work status were related to alcohol use among adolescents. Higher proportion of the adolescents associated alcohol use with heightened sexual performance. Health education strategies (public enlightenment, peer education and life skills training) against adolescent alcohol use is recommended.

Keywords: Sachet alcohol, risky sexual behavior, Adolescents.

DOI: https://dx.doi.org/10.4314/ahs.v20i1.5

Cite as: Oluwaseunfunmi A, Ademola A. Use of sachet alcohol and sexual behaviour among adolescents in Ibadan, Nigeria. Afri Health Sci. 2020;20(1):14-27. bttps:// dx.doi.org/10.4314/ahs.v20i1.5
\end{abstract}

\section{Introduction}

Globally, alcohol is the most widely used psychoactive substance. The use of alcohol beverages has been an integral part of many cultures for thousands of years, even till this present time. ${ }^{40} \mathrm{It}$ is the only psychotropic substance accepted and even encouraged by society, and so it is readily available. ${ }^{15}$ Improvements in marketing and sales of alcohol industry over the years have increased the availability and consumption of alcohol. ${ }^{3}$

\section{Corresponding author:}

Oluwaseunfunmi Arasi, Youth Empowerment Foundation, Monitoring \& Evaluation Department.

Email: oluwaseunfunmi.arasi@yahoo.com
The most recent means of alcohol packaging prevailing in Nigeria and other African countries is sachet waterproofs spirits. ${ }^{13,28}$ Therefore, the pattern of use, the users and reason(s) have changed significantly, especially among young drinkers like the adolescents. ${ }^{12}$

Generally, alcoholic beverages can be broadly categorized into three groups based on their content and source, and they are beer, wines and spirits ${ }^{11,13,31}$ Beers usually contain 4 to 8 percent of alcohol. ${ }^{13}$ Wines contain about 10 to 22 percent of alcohol, while spirits $(40 \%-60 \%)$ tend to be "harder" or more likely to lead to intoxication than beer or wine. Majority of the banded sachet liquors are spirits, with a street name 'Pelebe'. Sachet liquor is small, slim and portable sachet containing alcohol that comes three sizes: $30 \mathrm{mls}, 35 \mathrm{mls}$ and $50 \mathrm{mls}$; and mostly sold between $\$ 0.1$ and $\$ 0.2$ each. Sa-

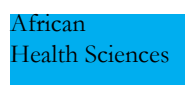

(C) 2020 Arasi O et al. Licensee African Health Sciences. This is an Open Access article distributed under the terms of the Creative commons Attribution License (https://creativecommons.org/licenses/BY/4.0), which permits unrestricted use, distribution, and reproduction in any medium, provided the original work is properly cited. 
chet liquors are readily available for sale at different outlets including beer shops, bus stations, pharmaceutical shops, and super- markets. ${ }^{13}$

Alcohol use by adolescents is a major health concern. The use of alcohol during the teenage years is a common phenomenon in many societies; it is the primary contributor to the leading causes of adolescent death. ${ }^{7,29,32}$ Harmful use of alcohol is linked with noncommunicable diseases like cancer, liver diseases; infectious diseases like tuberculosis; injuries and acci- dents. Globally, approximately three-fourths of ado- lescents have tried alcohol by the end of high school. ${ }^{26}$ Also, in the class of psychoactive substances like tobacco, Indian hemp, morphine, cocaine, heroin, alcohol, caffeine, barbiturates, amphetamines, alcohol is the most commonly used by adolescents. ${ }^{1,31}$ In Nigeria, there are laws restricting alcohol sale and consumption, but these laws are poorly en- forced. It is observed that alcohol is not only sold in un- registered premises, but hawkers of spirits sell around school premises, motor parks and television viewing centres in Nigeria.

In many sub-Saharan African countries like Kenya for example, ever drinking prevalence of up to $15 \%$ was found among secondary school students. A particular study from South Africa also reported an alcohol use prevalence of $39.1 \%$ among high school adolescents, another one reported 54\%, ${ }^{16}$ while in southern Ethiopia, a prevalence of $57.7 \%$ was found. ${ }^{32}$ Two Ghanaian studies con- ducted among secondary school students and among nationally- representative samples of inand out-of- school youth found that the prevalence of lifetime alcohol use was approximately $25 \% .^{18}$

In an article called 'Swimming with Crocodiles', ${ }^{25}$ Odejide, Omigbodun, Ajuwon et al. reported that peers and parents influenced drinking among the young people, curiosity was the major reason for alcohol consumption. Adenugba \& Ijagbone ${ }^{2}$ in a study found a prevalence of alcohol consumption of $37 \%$ and established socio-economic status of adolescents' family to be a predictor of alcohol use, and male sex to be a correlate of alcohol use, Atilola, Ayinde \& Adeitan ${ }^{5}$ recorded a prevalence of $21.4 \%$, while Durodola ${ }^{13}$ recorded a higher prevalence of $52 \%$ among secondary school students in Ibadan. Many risk factors for alcohol use have been document- ed in literature. Correlates of alcohol use include demo- graphic factors such as gender, ${ }^{37}$ age,${ }^{34}$ monthly income, living arrangement, attitudes toward alcohol use, perceived susceptibility of alcohol use, perceived self-efficacy, peer drinking, relatives drinking, accessi- bility of alcohol, and exposure to either anti-alcohol campaigns or to alcohol advertising as well as owner- ship of alcohol promotional items (souvenirs such as branded t-shirts, lighters, matches, hats, or sunglasses). ${ }^{22,35,36,40}$ Several studies have demonstrated relationship between alcohol use and sexual and reproductive health of ad- olescents. ${ }^{4,10}$ The link between alcohol use and sex has been explained through disinhibiting effect of alcohol. According to alcohol myopia theory which states that the acute disinhibitory effects of alcohol reduce the ability to process complex information (such as long- term goals), immediate and salient goals (such as sexual arousal) influence behavior more strongly. ${ }^{30}$

The sexual risk behaviours that are commonly linked with alcohol use are: early sexual activity, unprotected sexual intercourse exposing the adolescent to sexually transmitted infections (STI) and HIV, teenage pregnancies and sexual intercourse with multiple partners. ${ }^{6,14,20,33}$ It was also reported by Morhason-Bello, Oladokun, and Enakpene et al. ${ }^{27}$ while describing the sexual behavior of in-school adolescents in secondary schools in Ibadan that $28.3 \%$ of the respondents are sexually active and $77.2 \%$ of the sexually experienced respondents admitted that their first sexual exposure was unplanned.

Furthermore, alcohol is commonly used as a sex facilita- tor, perceived enhancement of confidence to approach the opposite sex; also as a symbol of masculinity (which is often linked to the ability to have multiple partners, imbibe alcohol and engage in promiscuous behavior). ${ }^{38}$ Based on alcohol expectancy theory, one of the reasons some adolescents use alcohol is their expectation that alcohol facilitates sexual drive, sexual effect and decreases sexual inhibitions. Royal College of Physicians ${ }^{33}$ reported that people feel more confident sexually if they have drunk alcohol, and can also be used afterwards as an explanation to legitimize the behavior. Although several studies have been conducted on use of alcohol among adolescents, none have focused on alcohol available in sachet. Alcohol in sachets is cheaper, affordable and easily accessible, as they are sold even by petty traders who own stalls that are available everywhere in rural and urban communities in Nigeria. 
Hence, this study sought to find out the use of liquors in small sachets by adolescents, providing insight into the pattern of use of this class of alcohol and their relationship with sexual behavior among this population.

\section{Method}

\section{Setting for the study}

Ibadan, the setting for the study, is a cosmopolitan metropolis of approximately 3.5 million people. The study was conducted in Ibadan South East which is one of the five Local Government Areas (LGAs) carved out of the defunct Ibadan Municipal Government (IMG). It is divided into twelve (12) political wards for easy administration; and its population as at the most recent population census in 2006 was 122,756 (National Population Commission, 2010).

This LGA accommodates some of the core slum areas in Ibadan such as Mapo, Eleta, Elekuro, Odinjo, Oke Oluokun, Kobomoje among others. These areas are highly densely populated with inadequate or no access to infrastructure and social amenities like roads, potable water, hospitals, etc.

Majority of the people that live within the Local Government are traders, artisans and drivers of commercial vehicles. There are markets such as Owode market at Odo-Oba, Ile Titun market, Fowl market at Old Molete part among others. There are many petty traders who sell alcohol and cigarette at motor parks, bus stops, along the streets, the crannies of the communities. Many of the male adults are engaged in businesses like commercial driving, tailoring, welding, trading among others; while the women are involved in trading in markets and streets, tailoring and some are civil servants.

\section{Study population}

The study population consists of adolescents (aged 10 - 19 years) who are students, workers, and apprentices within Ibadan South-East local government area (district) as at September, 2014, the period which the data for this study was obtained.

\section{Sampling procedures}

The sample size for the study was 390. Simple random sampling, through the use of ballot, was adopted in selecting four (4) wards and specific communities in Ibadan South East Local Government Area; bottle-spinning was used for the selection of streets for the administration of instruments in this study. Each selected area was combed to recruit one hundred and five (105) adolescents found by proxy, who were willing to participate in the study to make up the total sample size. The four (4) communities, where the quantitative sampling was done, were also used for the qualitative IDI sampling. The IDI was conducted with five (5) adolescents from each community; five (5) males through purposive sampling, thereby selecting identified 'Pelebe' users from the quantitative process who were willing to participate in the interview.

\section{Measures}

Both quantitative (questionnaire) and qualitative (Indepth interview) measures were used for data collection. A 61-item questionnaire was used and it was divided into six sections for ease of administration.

Section A consisted of eight (8) questions for documenting the demographic characteristics and the general profile of liquor in small sachet users; Section B contained ten (10) questions for determining the level of knowledge of the effects of alcohol. Section $C$ contained nineteen (19) questions addressing the pattern of use of liquor in small sachet among the adolescents while section D (seven questions) focused on the accessibility to liquor in small sachet. Section E contained nine (9) questions that address the perception of adolescents on liquor in small sachet and section F contained eight (8) questions that sought to establish the sexual risky behaviours of respondents.

The questionnaire was administered using face-toface interview. This method was used instead of the self-completed method because the literacy skills of the respondents could not be ascertained as they were not all learned.

The qualitative method was In-depth interview with conducted with five (5) adolescents from each community; five (5) males through purposive sampling, thereby selecting identified 'Pelebe' users who were willing to participate in the interview.

\section{Data collection procedures}

Each potential respondent was approached and informed about the purpose of the study and that data collected would be used for research purpose and that participation in it was voluntary. The consent form was given to potential respondents to read and digest 
(also made available in Yoruba language for ease of comprehension for those who were not proficient in English). Only the adolescents who gave voluntary informed consent by signing or thumb printing the consent forms participated in this research. Of the 420 respondents invited to participate in the study, 390 agreed to do so, giving a response rate of about $93 \%$. Also, approval was provided by the Ethics Committee of the Oyo State Ministry of Health. In-depth interviews were recorded on audio-tapes after interviewees provided informed consent.

Before the commencement of the in-depth interview, the selected participants were duly informed of the purpose of the research, their voluntary participation and consent; and the confidentiality of information received from them which were strictly for the purpose of the research. A digital voice recorder was used for collecting data, the interviews were timed and done in seclusion to ensure confidentiality and freedom of expression.

\section{Data analysis}

The data collected was checked for completeness and accuracy in the field. Serial number was assigned to each questionnaire for easy identification and for correct data entry and analysis. The data was entered and analyzed using SPSS statistical tool Version 20.0. The quantitative data were analyzed using descriptive and inferential statistics at $\mathrm{p}<0.05$; while the qualitative data was analyzed using thematic approach of content analysis. The recorded interviews were transcribed and subjected to thematic analysis with verbatim quotations.

\section{Results}

\section{Respondents' demographic data}

There were more males $(61.8 \%)$ than females $(38.2 \%)$ in the sample. Their ages ranged from $10-19$ (divided into two groups according to Nigeria Demographic and Health Survey, NDHS 2013: $(10-14)$ and (15 - 19)). There were equal number of respondents who fell within the early $(10-14$ years $)$ and late adolescence (15 - 19 years), i.e. 195 adolescents were within the age bracket $10-14$ years and 195 adolescents were also within the age bracket $15-19$ years. The mean age of the respondents was $14.67 \pm 2.60$ years with a range of $10-19$ years. Of the total respondents in this study, $280(71.8 \%)$ were students in schools, $43(11 \%)$ were apprentices while $67(17.2 \%)$ were working (Table 1). 
Table 1 - Socio-demographic Characteristics $(n=390)$

\begin{tabular}{|c|c|c|}
\hline Characteristics & No. & $\%$ \\
\hline \multicolumn{3}{|l|}{$\overline{\text { Sex }}$} \\
\hline Males & 241 & 61.8 \\
\hline Females & 149 & 38.2 \\
\hline \multicolumn{3}{|l|}{ Age Groups* } \\
\hline $10-14$ years & 195 & 50.0 \\
\hline $15-19$ years & 195 & 50.0 \\
\hline \multicolumn{3}{|l|}{ School/Work Status } \\
\hline In-school & 280 & 71.8 \\
\hline Apprentice & 43 & 11.0 \\
\hline Working & 67 & 17.2 \\
\hline \multicolumn{3}{|c|}{ Highest Educational Qualification } \\
\hline No qualification** & 62 & 15.9 \\
\hline Primary school & 165 & 42.3 \\
\hline Junior secondary school & 143 & 36.7 \\
\hline Senior secondary school & 20 & 5.1 \\
\hline \multicolumn{3}{|l|}{ Religion } \\
\hline Christianity & 104 & 26.7 \\
\hline Islam & 282 & 72.3 \\
\hline Traditional & 4 & 1.0 \\
\hline \multicolumn{3}{|l|}{ Family type } \\
\hline Monogamy & 201 & 51.5 \\
\hline Polygamy & 189 & 48.5 \\
\hline \multicolumn{3}{|l|}{ Birth Order } \\
\hline First born & 104 & 26.7 \\
\hline Middle born & 202 & 51.8 \\
\hline Last born & 77 & 19.7 \\
\hline Only child & 7 & 1.8 \\
\hline \multicolumn{3}{|c|}{ People Respondents Live with } \\
\hline Parents & 167 & 42.8 \\
\hline Grandparents & 56 & 14.4 \\
\hline Single Parent & 114 & 29.2 \\
\hline Relatives & 14 & 3.6 \\
\hline Independent & 39 & 10.0 \\
\hline
\end{tabular}

*Mean age of respondents $=14.67 \pm 2.6$

** No qualification - Adolescents who have not completed primary school education, but still in school; or those who dropped out of school without completing primary education.

Majority $(72.3 \%)$ of the respondents practice Islamic religion.

Alcohol Use

Exactly half $(50 \%)$ of the respondents had ever taken alcohol, a little less than half $(44.9 \%)$ had ever taken sachet liquor, while 39.5\% were current users of sachet liquor. Table 2 shows details of how these prevalence rates differ by sex. 
Table 2 - Prevalence of Alcohol Use by Sex

\begin{tabular}{llll}
\hline & $\begin{array}{l}\text { Male } \\
(\mathbf{n}-241)\end{array}$ & $\begin{array}{l}\text { Female } \\
(\mathbf{n}-149)\end{array}$ & $\begin{array}{l}* \text { Total } \\
\mathbf{( N = 3 9 0 )}\end{array}$ \\
\hline Ever use of alcohol & 143 & 52 & 195 \\
& $(59.3 \%)$ & $(34.9) \%$ & $(50 \%)$ \\
Current use of alcohol & 122 & 42 & 164 \\
& $(50.6) \%$ & $(28.2 \%)$ & $(42.1 \%)$ \\
Ever use of 'Pelebe' & 127 & 48 & 175 \\
& $(52.7 \%)$ & $(32.2 \%)$ & $(44.9 \%)$ \\
Current use of 'Pelebe' & 114 & 40 & 154 \\
& $(47.3 \%)$ & $(26.9 \%)$ & $(39.5 \%)$ \\
\hline
\end{tabular}

*This column represents the prevalence rates of the different categories.

Furthermore, Table 3 shows details of how the prevalent rate of current use of liquor sachets ('Pelebe') varies across sex, age groups and school/work status. By sex, more males than females took 'Pelebe'; by age, the older adolescents took 'Pelebe' more than the younger adolescents; while the class of working adolescents took alcohol most.

Table 3 - Current Use of 'Pelebe' by Sex, Age Group and School/Work Status ( $\mathrm{n}=390)$

\begin{tabular}{llll}
\hline & Use of 'Pelebe' & Total \\
\hline Sex & YES & NO & \\
Male & 114 & 127 & $\mathbf{2 4 1}$ \\
& $(47.3 \%)$ & $(52.7 \%)$ & \\
Female & 40 & 109 & $\mathbf{1 4 9}$ \\
& $(26.8 \%)$ & $(73.2 \%)$ & \\
Age Group & 62 & 133 & $\mathbf{1 9 5}$ \\
$10-14$ & $(31.8 \%)$ & $(68.2 \%)$ & \\
& 92 & 103 & $\mathbf{1 9 5}$ \\
$15-19$ & $(47.2 \%)$ & $(52.8 \%)$ & \\
& & & \\
School/Work Status & 91 & 189 & $\mathbf{2 8 0}$ \\
In-School & $(32.5 \%)$ & $(67.5 \%)$ & \\
& 23 & 20 & $\mathbf{4 3}$ \\
Apprentice & $(53.5 \%)$ & $(46.5 \%)$ & \multirow{2}{*}{$\mathbf{6 7}$} \\
& 40 & $(40.3 \%)$ & \\
Working & $(59.7 \%)$ & & \\
& & &
\end{tabular}

\section{Sexual Behaviour}

Approximately $30 \%$ of the respondents were sexually active, with more males than females $(\mathrm{p}<0.05)$ (see Table 4). As shown on Table 5, older adolescents were more sexually active than younger adolescents. Table 6 shows that only $19 \%$ of the in-school adolescents were sexually active while $65.7 \%$ of those working were sexually active $(\mathrm{p}<0.05)$. 
Table 4 - Sexually Active Respondents by Sex (Chi-square, $\mathrm{p}<0.05$ )

\begin{tabular}{|c|c|c|c|}
\hline & \multicolumn{3}{|c|}{ Sexually Active } \\
\hline & YES & NO & Total \\
\hline \multicolumn{4}{|l|}{ Sex } \\
\hline Male & $\begin{array}{l}88 \\
(36.5 \%)\end{array}$ & $\begin{array}{l}153 \\
(63.5 \%)\end{array}$ & 241 \\
\hline Female & $\begin{array}{l}31 \\
(20.8 \%)\end{array}$ & $\begin{array}{l}118 \\
(79.2 \%)\end{array}$ & 149 \\
\hline Total & $\begin{array}{l}119 \\
(30.5 \%)\end{array}$ & $\begin{array}{l}271 \\
(69.5 \%)\end{array}$ & 390 \\
\hline
\end{tabular}

Table 5 - Sexually Active Respondents by Sex and Age

\begin{tabular}{llll}
\hline & $\begin{array}{l}\text { Age Groups } \\
\mathbf{1 0}-\mathbf{1 4}\end{array}$ & $\mathbf{1 5 - 1 9}$ & Total \\
\hline Sex & & & \\
Male & 14 & 74 & 88 \\
& $(15.9 \%)$ & $(84.1 \%)$ & \\
Female & 7 & 24 & 31 \\
& $(22.6 \%)$ & $(77.4 \%)$ & \\
& $\mathbf{2 1}$ & $\mathbf{9 8}$ & $\mathbf{1 1 9}$ \\
Total & $(\mathbf{1 7 . 6 \% )}$ & $\mathbf{( 8 2 . 4 \% )}$ & \\
\hline
\end{tabular}


Table 6 - Sexually Active Respondents by School/Work Status (Chi-square, $p<0.05$ )

\begin{tabular}{llll}
\hline & $\begin{array}{l}\text { Sexually Active } \\
\text { YES }\end{array}$ & NO & Total \\
\hline $\begin{array}{l}\text { School/Work Status } \\
\text { In-school }\end{array}$ & 54 & 226 & 280 \\
& $(19.3 \%)$ & $(80.7 \%)$ & \\
Apprentice & 21 & 22 & 43 \\
& $(48.8 \%)$ & $(51.2 \%)$ & \\
Working & 44 & 23 & 67 \\
& $(65.7 \%)$ & $(34.3 \%)$ & \\
Total & $\mathbf{1 1 9}$ & $\mathbf{2 7 1}$ & $\mathbf{3 9 0}$ \\
\hline
\end{tabular}

Table 7 indicates that $37.3 \%$ of the sexually active adolescents had multiple sexual partners: $34 \%$ of sexually active in-school adolescents had multiple sexual partners while $40.9 \%$ of working respondents had multiple sexual partners.

Table 7 - Multiple Sexual Partners by School/Work Status (Chi-square, $p<0.05$ )

\begin{tabular}{|c|c|c|c|c|}
\hline \multirow{2}{*}{\multicolumn{2}{|c|}{ Educational Status }} & \multicolumn{3}{|c|}{ Multiple sexual partner } \\
\hline & & YES & $\mathrm{NO}$ & Total \\
\hline & \multirow[t]{2}{*}{ In-school } & 18 & 35 & 53 \\
\hline & & $(34.0 \%)$ & $(66.0 \%)$ & \\
\hline & \multirow[t]{2}{*}{ Apprentice } & 8 & 13 & 21 \\
\hline & & $(38.1 \%)$ & $(61.9 \%)$ & \\
\hline & \multirow[t]{2}{*}{ Working } & 18 & 26 & 44 \\
\hline & & $(40.9 \%)$ & $(59.1 \%)$ & \\
\hline Total & & $44(37.3 \%)$ & $74(62.7 \%)$ & 118 \\
\hline
\end{tabular}

Table 8 shows that $33.6 \%$ of the sexually active respondents took alcohol before sex while $63 \%$ did not use condom in the last sexual episode. The respondents indicated some reasons for using condom, most of which were: protection from infections, prevention of pregnancy, and sexual arousal. However, majority $(79.5 \%)$ used condom in the last sex used condom for protection from diseases/infections.
This study sought to establish a relationship between sachet liquor use and sexual behavior, a significant relationship was found between current sachet liquor use and unsafe sex. The test of Chi-square confirmed that most of the respondents $(70.7 \%)$ who did not use condom in the last sexual episode were current alcohol users (those who took sachet liquor in the month preceding survey) $(\mathrm{p}<0.05)$. Also, $75 \%$ of respondents who took alcohol before sex did not use condom (see Table 9). 
Table 8 - Alcohol use of the sexually active respondents during their last sexual episode and condom use.

\begin{tabular}{llll}
\hline & YES & NO & Total \\
\hline Use of alcohol before sex & 40 & 79 & 119 \\
& $(33.6 \%)$ & $(66.4 \%)$ & \\
Use of alcohol by sex partner before sex & 18 & 101 & 119 \\
& $(15.1 \%)$ & $(84.9 \%)$ & \\
Use of condom during last sex episode & 44 & 75 & 119 \\
& $(37 \%)$ & $(63 \%)$ & \\
\hline
\end{tabular}

Table 9 - 'Pelebe' use before sex and condom use in last sexual episode (Chi-square, $\mathrm{p}<$ $0.05)$

\begin{tabular}{|c|c|c|c|}
\hline & \multicolumn{3}{|c|}{$\begin{array}{l}\text { Use of condom in the last sexual } \\
\text { episode with sexual partner }\end{array}$} \\
\hline & YES & $\mathrm{NO}$ & Total \\
\hline \multicolumn{4}{|c|}{$\begin{array}{l}\text { Use of alcohol before sex with your } \\
\text { partner }\end{array}$} \\
\hline \multirow[t]{2}{*}{ YES } & & & 40 \\
\hline & $(25.0 \%)$ & $(75.0 \%)$ & \\
\hline NO & $\begin{array}{l}34 \\
(43.0 \%)\end{array}$ & $\begin{array}{l}45 \\
(57.0 \%)\end{array}$ & 79 \\
\hline Total & 44 & 75 & 119 \\
\hline
\end{tabular}

Furthermore, a regression analysis was performed to identify the determinants of safe sex. The result showed that 'Pelebe' use was a predictor of unsafe sex, as those who were current users of 'Pelebe' were nine (9) times more likely to practice unsafe sex than those who did not take 'Pelebe' (see Table 10). 
Table 10: Logistic Regression Model of Safe Sex by Sex, Age, Educational Status and 'Pelebe' Use

\begin{tabular}{|c|c|c|c|c|c|c|}
\hline \multirow[b]{2}{*}{ Sex } & \multicolumn{3}{|c|}{ Safe Sex } & \multirow[t]{2}{*}{$\operatorname{Exp}(B)$} & \multirow[t]{2}{*}{$\mathrm{Cl}$} & \multirow[t]{2}{*}{$\mathbf{P}$} \\
\hline & YES & NO & Total & & & \\
\hline Male & 34 & 53 & 87 & \multirow{3}{*}{0.98} & \multirow{3}{*}{$0.28-3.49$} & \multirow{3}{*}{0.97} \\
\hline Female & 10 & 21 & 31 & & & \\
\hline \multirow[t]{2}{*}{ Total } & 44 & 74 & 118 & & & \\
\hline & \multicolumn{3}{|c|}{ Safe Sex } & & & \\
\hline Age & YES & NO & Total & \multirow{4}{*}{1.68} & \multirow{4}{*}{$0.41-6.9$} & \multirow{4}{*}{0.47} \\
\hline $10-14$ & 4 & 16 & 20 & & & \\
\hline $15-19$ & 40 & 58 & 98 & & & \\
\hline Total & 44 & 74 & 118 & & & \\
\hline Educational & \multicolumn{3}{|c|}{ Safe Sex } & \multirow{6}{*}{1.01} & \multirow{6}{*}{$0.16-2.01$} & \multirow{6}{*}{0.98} \\
\hline Status & YES & NO & Total & & & \\
\hline In-School & 18 & 35 & 53 & & & \\
\hline Apprentice & 8 & 13 & 21 & & & \\
\hline Working & 18 & 26 & 44 & & & \\
\hline \multirow[t]{2}{*}{ Total } & 44 & 74 & 118 & & & \\
\hline & Safe & & & & & \\
\hline Pelebe' Use & YES & NO & Total & \multirow{4}{*}{9.16} & \multirow{4}{*}{$0.92-91$} & \multirow{4}{*}{0.05} \\
\hline YES & 24 & 52 & 76 & & & \\
\hline NO & 4 & 1 & 5 & & & \\
\hline Total & 28 & 53 & 81 & & & \\
\hline
\end{tabular}

According to the findings of in-depth interview, the participants believed alcohol gave extra energy for sexual pleasure and they were also aware of the effects of the 'Pelebe' in putting them at risk of improper use of condom. Below is one of the typical expressions of the participants on use of alcohol in enhancing sexual performance:

- You know what, for me, I have one 'Iya Sule' in my area when I go to her that I want to have sex with my girl, she will give me 'Opa eyin' (herbal concoction for pile). When I feel the concoction is not working, to be sincere, I sometimes take Regal, because I know that Regal will make me high and aroused to perform well. I might be conscious but I might lose some consciousness. But that thing I'm doing can't be like I'm unconscious, for me, if I take it, my sight will be blurred, the girl I'm having sex with will look like 2 or 3 sometimes, but I will know where I'm focused to go or penetrate, that's for me

\section{Discussion}

A large proportion of the adolescents who participated in this study as at the time the study was carried out, did not have the lowest educational qualification of Primary School Leaving Certificate; some of which had dropped out of school. This is very critical in the issues of adolescent health and its determinants. Several studies suggest a positive relationship between being substance use and an individual's educational level; this has been confirmed to be one of the social determinants of adolescents' substance use, abuse and harm. ${ }^{17,19,21,23,24,39}$ The result revealed that education is a protective factor of adolescent alcohol use and risky sexual behav- ior. Kleinjan \& Engels ${ }^{19}$ submitted that smoking, drinking, and cannabis use are more prevalent among youths from lower educational backgrounds compared to youths with higher educational attainment. Adolescent use of alcohol could also contribute to the high 
rate of school drop-out, as alcohol use contributes to poor academic performance. ${ }^{23}$ Therefore, low educational attainment is a risk factor observed in this study for positive perception of alcohol, adolescents' alcohol use, dangerous pattern of alcohol use, and engaging in risky sexual behaviours. It further implies risk of more dangerous social vices such as smoking, violence, drinking and driving among others. Other protective factors not evident in this study are strong religious beliefs, positive peer influence and good parental control.

Exactly half of the participants in this study had taken alcohol at least once, while about 39\% were current users of 'Pelebe'. This is similar to previous studies on adolescent alcohol use in Nigeria which has established that alcohol use is very common among adolescents in the country. Atilola et al..$^{5}$ conducted a study on adolescent alcohol and substance use among a cohort of school-going adolescents in Nigeria. The results showed that about $21 \%$ of the adolescents had used alcohol or any other substance in the preceding twelve (12) months. This is also in agreement with the find- ings of Adenugba \& Ijagbone ${ }^{2}$ and Oshodi et al. ${ }^{29}$ However, Durodola ${ }^{13}$ reported a little higher prevalence of about $50 \%$ also among secondary school adolescents. Also in South Africa, Hoque \& Ghuman ${ }^{16}$ reported more than half $(54 \%)$ of the adolescents had consumed alcohol at some time in their life.

Though more than a quarter of the participants are sexually active, majority of the sexually active adolescents in this study are the apprentice and working population. About $66 \%$ of the working participants are sexually active, while most of them are in their late adolescence. Also, about $41 \%$ of working adolescents have multiple sexual partners while a fewer percentage of the sexually active in-school participants do. This is divergent find- ing from Morhason-Bello et al. ${ }^{27}$ who concluded that in-school adolescents practiced unsafe sexual activity and they are therefore predisposed to STI/HIV and other reproductive health risks.

This study also revealed that $75 \%$ of those who used alcohol before sex did not use condom, an indication of one of the dis-inhibitory effects of alcohol. This find- ing affirms the researches that have established links between alcohol and risky sexual behaviours ${ }^{28}$.

Cooper ${ }^{8}$ established that that drinking prior to intercourse is associated with risky partner choice as well as with decreased risk discussion on that occasion. Alcohol use is one of the contributing factors to the continuous rise in the incidence of HIV/AIDS among youths in Nigeria, particularly new infection cases. The findings of this study reveals that majority of the sexually active respondents who take alcohol don't use condom, an indication of unprotected sex. This has strong implications for sexually transmitted infections (STI) including HIV, unwanted pregnancies, unsafe abortions, teenage motherhood, high school drop-out, emotional instability and poverty. $\mathrm{RCP}^{33}$ asserts also that young people have the highest rate of sexually transmitted infections.

\section{Implications for health education and social poli- cies}

It is evident in this study that a large proportion of adolescents have very low educational level, though some of them are still in school. Furthermore, with studies establishing a positive relationship between adolescent alcohol use and high rate of dropping out of school, it is pertinent to address the issue of adolescent alcohol use by all relevant stakeholders in adolescent health; such as parents/guardians, government, school authorities including teachers, media, Law Enforcing Agencies, among others. This findig provides a queue to one of ways of improving literacy and socioeconomic status of the country.

There is also need to train teachers, parents and guardians on the effect of alcoholic drinks on adolescents, laws regulating alcohol sales and use, access of the under-aged to alcoholic drinks and consequences of alcohol use. Many parents don't even know their children/ wards take alcohol, hence the need to sensitize them on the current pattern of adolescent alcohol use. These training programmes need to actively involve the students, teachers, parents and relevant authorities for those in school settings and the adolescents, parents/ guardians, liquor sellers among others for those in the community setting.

Peer education will also be very useful as a tool for im- 
proving the awareness and promoting health among the adolescents, as it has been used in addressing adolescents sexual and reproductive health issues in previous intervention programmes. Moreover, many of the respondents in this study associated alcohol use with improved sexual performance, and this ideology is shared among the adolescents.

\section{Conclusion}

According to the findings of this study, use of sachet liquor is a common phenomenon among adolescents, cutting across sexes, age groups, and school/work status. The trend observed points to the fact that prevalence of 'Pelebe' increases towards the male sex, older adolescents and out-of-school adolescents; which is not different from what has been observed in previous researches.

This study also reveals a large proportion of participants are sexually active with more males than females and most of which are out-of-school. A lot of these findings have serious implications for Adolescent Sexual and Reproductive Health (ASRH). The level of practice of risky sexual behaviours (as defined in this study as multiple sexual partners and unprotected sex) among the participants calls for concern and actions.

It is also evident in this study that among those who are sexually active, majority engage in unprotected sex. However, many of the sexually active participants who take 'Pelebe' did not use condom in their last sexual episode. The regression analysis confirms 'Pelebe' use as a predictor of unsafe sex. This implies that use of alcohol is a deterrent in the sexual health of adolescents.

Some of the in-depth interview respondents who explained how adolescents use alcohol in boosting energy for improved sexual performance, corroborated on the findings of the quantitative aspect of this study which highlighted the link between alcohol use and risky sexual behavior, especially unprotected sex.

It is recommended that Health education strategies such as public enlightenment, peer education and life skills training should be adopted, involving all relevant stakeholders in adolescent health, in bridging the gaps in knowledge of alcohol effects, sexual health and misconceptions about sachet liquor. Also, relevant governmental agencies should rise to the implementation and enforcement of available laws and policies on alcohol advertisement, sales and use in schools and the commu- nities. The production of these sachets liquors should be banned completely.

\section{Limitations}

We acknowledge the two limitations of our study. First, the survey was conducted in just one out of the five LGA in Ibadan metropolis so findings cannot be generalized to the adolescents in Oyo state, let alone Nigeria. Secondly, the data on use of alcohol in sachet and sexual behavior are derived from self-reports which may difficult to verify. Nevertheless, the data on use of alcohol in sachet and sexual behavior among adolescents have contributed to our understanding of the relationship between these variables.

\section{References}

1. Abdu-Raheem BO. Sociological Factors to Drug Abuse and the Effects on Secondary School Students' Academic Performance in Ekiti and Ondo States, Nigeria. Contemporary Issues in Education Research. 2013;6(2):233- 40.

2. Adenugba AA, Ijagbone IO. Correlates of Alcohol Consumption among Adolescents in Ibadan North Local Government Area of Oyo State, Nigeria. Mediterranean Center of Social and Educational Research. 2012;3:251. 3. Adewuya AO. Validation of the alcohol use disorders identification test (audit) as a screening tool for alcohol-related problems among Nigerian university students. Alcohol and Alcoholism. 2005 Nov 1;40(6):575-7.

4. Asamoah BO, Agardh A. Alcohol consumption in relation to maternal deaths from induced-abortions in Ghana. Reproductive Health. 2012 Dec;9(1):10.

5. Atilola O, Ayinde O, Adeitan O. Beyond prevalence and pattern: problematic extent of alcohol and substance use among adolescents in Ibadan South-west Nigeria. African Health Sciences. 2013;13(3):777-84.

6. Choudhry V, Agardh A, Stafström M, Östergren PO. Patterns of alcohol consumption and risky sexual behavior: a cross-sectional study among Ugandan university students. BMC Public Health. 2014 Dec 1;14(1):128. 7. Committee on Substance Abuse. Alcohol use by youth and adolescents: a pediatric concern. Pediatrics. 2010 May 1;125(5):1078-87.

8. Cooper ML. Alcohol use and risky sexual behavior among college students and youth: evaluating the evidence. Journal of Studies on Alcohol, supplement. 2002 $\operatorname{Mar}(14): 101-17$.

9. Demographic N. Health Survey (NDHS)(2013). Household population and Housing characteristics. Na- 
tional Population Commission (NPC). Federal Republic of Nigeria, Abuja, Nigeria. 2013:11-29.

10. Diane M, Mary M, Gillmore R, Hoppe MJ, Gaylord J, Leigh BC, Rainey D. Adolescent drinking and sex: findings from a daily diary study. Perspectives on Sexual and Reproductive Health. 2003 Jul;35(4):162-8.

11. Dimelu MU, Agbo C, Igbokwe EM. Pattern of alcohol consumption and its effects on livelihood in selected rural communities of Enugu State, Nigeria. Asian Journal of Agriculture and Rural Development. 2011;1(393-2016-23905):69-79.

12. Dumbili E. Changing Patterns of Alcohol Consumption in Nigeria: An Exploration of Responsible factors and Consequences. A Journal of the BSA MedSoc Group.

13. Durodola, A. 2009. Secondary School Students' Knowledge, Perception and Exposure to Alcohol Advertisement in the Mass Media in Ibadan North Local Government Area, Nigeria. Ibadan. (Unpublished Dissertation)

14. Ekpenyong NS, Aakpege NY. Alcohol consumption pattern and risky behaviour: A study of University of Port Harcourt. IOSR Journal of Humanities and Social Science (IOSR-JHSS). 2014;19(3):1.

15. Granville-Garcia AF, Clementino MA, Gomes MD, Firmino RT, Ribeiro GL, Siqueira MB. Alcohol consumption among adolescents. Ciencia \& saude coletiva. 2014;19:7-16.

16. Hoque M, Ghuman S. Do parents still matter regarding adolescents' alcohol drinking? Experience from South Africa. International Journal of Environmental Research and Public Health. 2012 Jan;9(1):110-22.

17. Hyshka E. Applying a social determinants of health perspective to early adolescent cannabis use-An overview. Drugs: Education, Prevention and Policy. 2013 Apr 1;20(2):110-9.

18. Kabiru CW, Beguy D, Crichton J, Ezeh AC. Self-reported drunkenness among adolescents in four sub-Saharan African countries: associations with adverse childhood experiences. Child and Adolescent Psychiatry and Mental Health. 2010 Dec;4(1):17.

19. Kleinjan M, Engels RC. Middelengebruik: Determinanten en preventiemogelijkheden vanuit opvoeding, educatie en beleid.

20. Lavikainen HM, Lintonen T, Kosunen E. Sexual behavior and drinking style among teenagers: a population-based study in Finland. Health Promotion International. 2009 Jun 1;24(2):108-19.

21. Loring B. Alcohol and inequities: guidance for addressing inequities in alcohol-related harm. Copenha- gen, Denmark: World Health Organization; 2014. 22. Mamman H, Othman AT, Lian LH. Adolescent's and drugs abuse in Nigeria. Journal of Biology, Agriculture and Healthcare. 2014;4(1):5-9.

23. Mandelíková M. Adolescents Alcohol Consumption: Identification of determinants of probability to drink with special focus on social interaction.

24. Marketing A, People Y. Issues BrIeFINGs.

25. Martinic M, Measham F. Swimming with crocodiles: The culture of extreme drinking. Routledge; 2008 Jun 19.

26. Moreno MA, Furtner F, Rivara FP. Media influence on adolescent alcohol use. Archives of Pediatrics \& Adolescent Medicine. 2011 Jul 4;165(7):680-.

27. Morhason-Bello IO, Oladokun A, Enakpene CA, Fabamwo AO, Obisesan KA, Ojengbede OA. Sexual behaviour of in-school adolescents in Ibadan, SouthWest Nigeria. African Journal of Reproductive Health. 2008;12(2):89-97.

28. Okonkwo UU. Drinking in Lagos. "In a Paper presented at the $8^{\text {th }}$ Biennial International Conference on Drugs and Society in Africa, Chelsea Hotel Abuja 2008 (Vol. 23).

29. Oshodi OY, Aina OF, Onajole AT. Substance use among secondary school students in an urban setting in Nigeria: prevalence and associated factors. African Journal of Psychiatry. 2010;13(1).

30. Patrick ME, Maggs JL. Does drinking lead to sex? Daily alcohol-sex behaviors and expectancies among college students. Psychology of Addictive Behaviors. 2009 Sep;23(3):472.

31. Peltzer K, Ramlagan S. Alcohol use trends in South Africa. Journal of Social Sciences. 2009ade Jan 1;18(1):1-2.

32. Reda AA, Moges A, Wondmagegn BY, Biadgilign S. Alcohol drinking patterns among high school students in Ethiopia: a cross- sectional study. BMC Public Health. 2012 Dec;12(1):213.

33. Royal College of Physicians of London. Alcohol and Sex: A Cocktail for Poor Sexual Health. A Report of the Alcohol and Sexual Health Working Party. RCP. 34. Seaman P, Ikegwuonu T. Drinking to belong. York: Joseph Rowntree Foundation. 2010 Nov.

35. Swahn MH, Ali B, Palmier JB, Sikazwe G, Mayeya J. Alcohol marketing, drunkenness, and problem drinking among Zambian youth: findings from the 2004 Global School-Based Student Health Survey. Journal of Environmental and Public Health. 2011;2011.

36. Swahn MH, Palmier JB, Kasirye R. Alcohol exposures, alcohol marketing, and their associations with 
problem drinking and drunkenness among youth living in the slums of Kampala, Uganda. ISRN Public Health. 2013 Apr 30;2013.

37. Tur JA, Puig MS, Pons A, Benito E. Alcohol consumption among school adolescents in Palma de Mallorca. Alcohol and Alcoholism. 2003 May 1;38(3):2438. 38. UNAIDS W. UNAIDS/WHO AIDS Epidemic Update: December 2006.
39. World Health Organization. World Health Report 2011: Global status report on alcohol and health. Switzerland: World Health Organization. 2011.

40. World Health Organization. Global status report on noncommunicable diseases 2014. World Health Organization; 2014. 